\title{
International Journal of Development Education and Global Learning Editorial
}

The three articles in this issue, all based on research about the impact of development education and global learning on further and higher education in the UK, raise issues and pose questions that have been ongoing within this journal since it was established in 2008.

Each of the three papers reviews, through case studies, examples of practice and intervention to raise the profile and quality of global learning within further education colleges and teacher education. The article from the team at Liverpool Hope University (Bamber et al.), on measuring attitudes towards global learning among future educators, addresses the issue of short-term versus long-term changes in attitude and behaviour. Using an attitude inventory, based upon Thurstone scaling, it analyses changes in attitude among more than 150 undergraduate students planning to become primary school teachers. The findings show positive changes in attitudes towards global learning among females as well as eradication of the most negative attitudes towards global learning during the course of study.

The second article, by Stephen Scoffham from Canterbury Christ Church University, explores the challenges of developing a module on global learning for primary initial teacher education (ITE) students studying at a UK university. The research, like the Liverpool study, looks at the impact over a period of time, in this case three years. The findings indicate that many students developed their thinking about global issues but that there were some - a significant minority - who were much harder to reach. The findings also suggest that much of the learning was still at a relatively surface level. This very honest article highlights the complexities and challenges of promoting global learning themes within teacher education and the dangers of making the all-too-easy assumption that all you have to do is provide appropriate courses, learning opportunities, and support for global learning to increase.

The third article, from Bentall and McGough, based at the Institute of Education in London, looks at incorporating global learning within further education colleges. This area has been the subject of very little attention by this journal or wider academic research, and it identifies, like the other two articles, some key challenges in 
promoting global learning themes within courses. The findings show a range of levels of engagement, with much learning about, and enthusiasm for, global issues. There is some evidence of a few students moving beyond charitable notions of development and of the positive impact of first-hand overseas experience, resulting in some forms of change and transformation. But there is also evidence of the continuing influence of a desire to help and support partners overseas based on a traditional charitable mentality. The findings highlight, too, responses and forms of resistance by students to some of the more transformative aspects of global learning. Finally, this article investigates an important issue, the conceptual framework needed to interpret these differing responses towards global learning within further education.

All three articles are therefore considerably significant both in terms of identifying how best to intervene within various structures in education and what to expect in terms of outcomes and impact. Above all, they show the need for continuing dialogue on the relationship between evaluation and research. They also highlight the value that more academically based approaches can provide in identifying ways in which differing approaches can raise understanding about global and development issues and what the learners do with this increased understanding.

\section{Douglas Bourn}

Editor

Director, Development Education Research Centre, Institute of Education, University of London 